\title{
Intense Molar Circular Dichroism in Fully Conjugated All-Carbon Macrocyclic 1,3-Butadiyne Linked pseudo-meta [2.2]Paracyclophanes
}

Eric Sidler, ${ }^{\text {ał }}$ Patrick Zwick, ${ }^{\text {ał }}$ and Marcel Mayor ${ }^{\star a, b, c}$

${ }^{*}$ To whom correspondence should be addressed

抽ese authors contributed equally to this work

aDepartment of Chemistry, University of Basel, St. Johanns-Ring 19, 4056 Basel, Switzerland

bInstitute for Nanotechnology (INT), Karlsruhe Institute of Technology (KIT), P. O. Box 3640, 76021 Karlsruhe, Germany

'Lehn Institute of Functional Materials (LIFM), School of Chemistry, Sun Yat-Sen University (SYSU), 510275 Guangzhou, China

marcel.mayor@unibas.ch, https://www.chemie1.unibas.ch/ mayor/ ORCID: 00000002-8094-7813

Eric Sidler ORCID: 0000-0001-7740-3869

Patrick Zwick ORCID: 0000-0003-2053-1768 


\section{Abstract}

The synthetic access to macrocyclic molecular topologies with interesting photophysical properties has greatly improved thanks to the successful implementation of organic and inorganic corner units. Based on recent reports, we realized pseudometa [2.2]paracyclophanes (PCPs) might serve as optimal corner units for constructing 3D functional materials, owing to their efficient electronic communication, angled substituents and planar chirality. Herein, we report the synthesis, characterization and optical properties of three novel all-carbon enantiopure macrocycles bearing three to five pseudo-meta PCPs linked by 1,3-butadiyne units. The macrocycles were obtained by a single step from enantiopure literature known dialkyne pseudo-meta PCP and were unambiguously identified and characterized by state-of-the-art spectroscopic methods. By comparing the optical properties to relevant reference compounds, we show that the pseudo-meta PCP subunit effectively elongates the conjugated system throughout the macrocyclic backbone, such that already the smallest macrocycle consisting of only three subunits reaches an astounding polymer-like conjugation length. Additionally, we show that the chiral pseudo-meta PCPs induce remarkable chiroptical response in the respective macrocycles, which increases non-linearly with the number of PCP units to unprecedented high molar dichroism values for all-carbon macrocycles of up to $1335 \mathrm{~L} \mathrm{~mol}^{-1} \mathrm{~cm}^{-1}$.

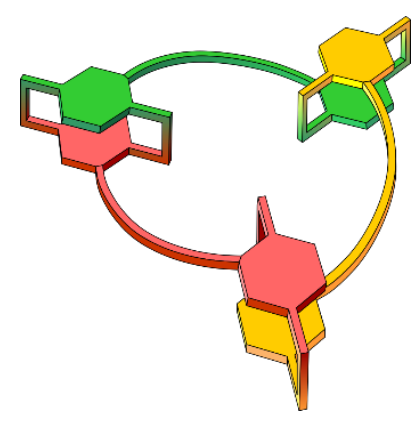




\section{Introduction}

The number of reports on carbon-based macrocyclic structures has seen a tremendous upward trend in recent years due to the promising photophysical properties and topological beauty such $\pi$-conjugated structures exhibit. The access to these -usually strained- macrocycles has also greatly improved due to the development of new synthetic methodologies. The necessity for strain overcoming synthetic strategies becomes clear when considering the planar and linear conformation that para-substituted benzene exhibit, which is the most found building block in $\pi$-conjugated macrocycles. One of the most prominent macrocyclic structure featuring only para-benzene units is the cycloparaphenylene (CPP) with its radially oriented $\pi$ surface, first synthesized in 2008 by Bertozzi and co-workers. ${ }^{1}$ The synthesis of these strained CPPs was enabled by the ingenious implementation of angled cyclohexadiene corner units that facilitate macrocyclization reactions and are reductively aromatized in a final reaction step. Since then, many new synthetic strategies to overcome strain have been developed. Among those belong for example the platinum (II) complex strategy, ${ }^{2}$ the cyclohexane corner strategy, ${ }^{3,4}$ the combination of Diels-Alder and retro-Diels-Alder reactions, ${ }^{5}$ or the utilization of ethylene bridges, ${ }^{6,7}$ which led to the synthesis of (gram scale) CPPs, zig-zag carbon nanobelts and cycloparaphenylene acetylenes (CPPAs). Beside the recently predominant para substitution pattern, meta-substituted benzene units have also found their way into carbon-based materials. They were implemented as branching points for the construction of larger dendrimers, ${ }^{8,9}$ as corner units for the formation of macrocycles, ${ }^{10-}$ 15 or as general building blocks for polyarylenes. ${ }^{16,17}$ Recently, they were also introduced into CPPs to enhance fluorescent properties. ${ }^{18}$ While meta-substituted benzenes do provide an ideal angle for easier incorporation into new carbon-based topologies, the electronic communication between the substituents is limited due to cross-conjugation, making them less ideal for conjugated materials. ${ }^{19}$ 


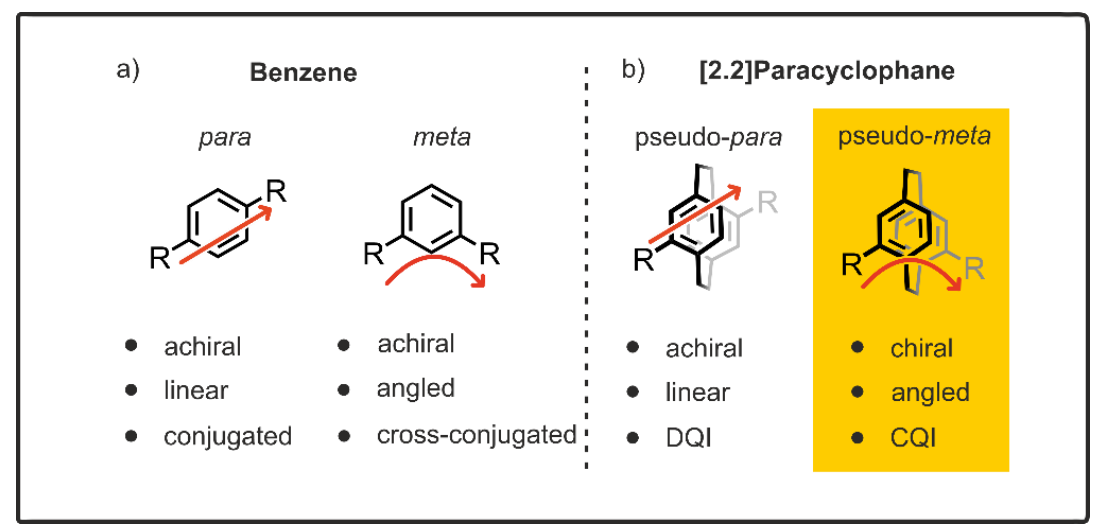

Figure 1. Comparison of chirality, directionality and electronics of para- and meta-substituted benzene (a), and pseudo-para- and pseudo-meta-substituted [2.2]paracyclophane (b).

[2.2]Paracyclophanes (PCPs) are moieties with two slightly bent face-to-face oriented benzene rings connected by two ethane bridges (Figure 1b). The different substitution patterns available in these structural units enable a large variety of distinct building blocks, making PCP a generally interesting subunit for 3D materials. ${ }^{21}$ This is why PCPs are not unknown in the field of new functional materials. They have been used among other things for the construction of dendrimer structures, ${ }^{22}$ macrocyclic metal complexes, ${ }^{23}$ or one-handed double helices. ${ }^{24}$ Recently, pseudo-para PCP was also incorporated into CPPs to investigate through-space conjugation ${ }^{25}$ and a fourfold substituted PCP was used for helical chirality stabilization in oligothiophene macrocycles. ${ }^{26}$ Triangle-shaped macrocycles consisting of peudo-ortho PCPs with either para-phenylene-ethynylene or biphenyl linkers ${ }^{27}$ were also reported, but their angle only allows the formation of limited ring sizes. ${ }^{28,29}$

In contrast to benzene, the behaviour of electronic communication in pseudo-para and pseudo-meta-substituted PCPs is reversed. This was shown by Yoshizawa and coworkers, who theoretically predicted weak charge transport in pseudo-para and pseudo-ortho PCPs, and increased charge transport in pseudo-meta PCPs according to frontier orbital analysis. ${ }^{30}$ Performing mechanically controlled break junction experiments, our group recently reported experimental evidence of this destructive and constructive quantum interference (DQI and CQI) effects in pseudo-para and pseudometa substituted PCPs, respectively, therefore confirming the theoretical prediction. ${ }^{31}$ With this finding, we figured that pseudo-meta PCPs might be ideal candidates for incorporation in $\pi$-conjugated materials. Unlike para-benzene, they combine optimal conjugation with an angled arrangement of the substituents, allowing construction of new types of topologies without the formation of excessive amounts of strain. Additionally, their angle facilitates macrocyclization, circumvents the need for specific 
corner units and their inherent chirality equips the materials with additional chiroptical properties. In this work, we thus show the synthesis, characterization and (chir)optical properties of three novel all-carbon macrocycles featuring several pseudo-meta PCP units connected by 1,3-butadiyne linkers. We further demonstrate that the utilization of pseudo-meta PCP skips the need for corner units, enables thorough conjugation throughout the macrocycles and induces a remarkable chiroptical response.

\section{Results \& Discussion}

\section{Design}

We envisioned to synthesize the cyclized 1,3-butadiyne linked pseudo-meta-PCPs $\left(R_{\mathrm{p}}\right) \mathrm{n}-1 \mathrm{n}$, where $\mathrm{n}$ represents the number of pseudo-meta-PCP units, by a simple alkyne homocoupling of enantiopure dialkyne $\left(R_{\mathrm{p}}\right)$-S1. Preliminary computational modelling suggested ring sizes bearing 3 to 6 PCP units in the backbone, although the geometry in the butadiyne linkers for both trimer $\left(R_{\mathrm{p}}\right)_{3}-\mathbf{1}_{3}$ and hexamer $\left(R_{\mathrm{p}}\right)_{6}-\mathbf{1}_{6}$ seemed to be unfavourable. The disconnection of the other enantiomers, $\left(S_{p}\right)_{n}-1 n$, can be performed analogously and leads to the enantiopure dialkyne $\left(S_{p}\right)-\mathbf{S 1}$. For reasons of simplicity, the synthesis and structural analysis are henceforth discussed exclusively for the $\left(R_{p}\right)$-enantiomers, but were performed equally with the $\left(S_{p}\right)$-enantiomers and provided similar results.
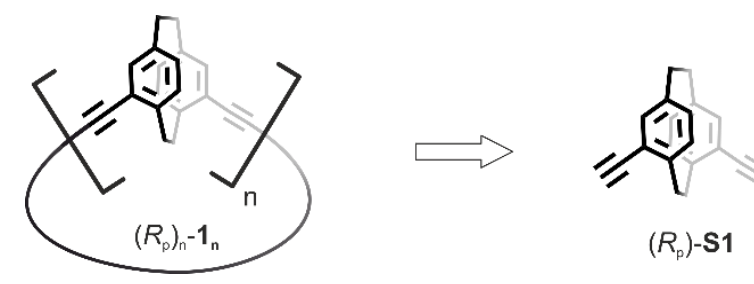

Scheme 1. Retrosynthesis of the designed 1,3-butadiyne linked pseudo-meta PCPs $\left(R_{\mathrm{p}}\right)$ - $\mathbf{1}_{\mathrm{n}}$, where $\mathrm{n}$ denotes the number of PCP units. Disconnection of the $\left(S_{p}\right)$-enantiomers can be done analogously, leading to $\left(S_{p}\right)-\mathbf{S} 1$.

\section{Synthesis and Characterization}

To obtain the desired macrocyclic 1,3-butadiyne linked PCPs $\left(R_{\mathrm{p}}\right)_{\mathrm{n}}-\mathbf{1} \mathrm{n}$, racemic dialkyne rac-S1 was first synthesized according to literature procedures. ${ }^{32}$ Unlike in the reported approach, the enantiomers were separated by chiral-phase high-performance liquid chromatography (HPLC) at the dialkyne stage in order to reduce the number of 
steps (see Supporting Information, Figure S 8). Subjecting the enantiopure dialkyne $(R \mathrm{p})$-S1 to palladium-catalyzed Glaser coupling conditions at low concentration (1 mM) in toluene at $80^{\circ} \mathrm{C}$, gave a complex mixture of open-chain polymers and oligomers beside the desired macrocycles $\left.\left(R_{\mathrm{p}}\right)_{3} \mathbf{1}_{3}, R_{\mathrm{p}}\right)_{4}-\mathbf{1}_{4}$ and $\left(R_{\mathrm{p}}\right)_{5} \mathbf{1}_{5}$. While trimeric macrocycle $\left(R_{\mathrm{p}}\right)_{3} \mathbf{1}_{3}(1.5 \%$ yield $)$ and tetrameric macrocycle $\left(R_{\mathrm{p}}\right)_{4}-\mathbf{1}_{4}(2.2 \%$ yield $)$ were readily purified by automated recycling gel permeation chromatography (GPC), pentameric macrocycle $\left(R_{\mathrm{p}}\right)_{5}-15$ (1.6\% yield) needed an additional purification step by normal-phase HPLC (see Supporting Information, Figure S 30).

The identity of the macrocycles was corroborated by ${ }^{1} \mathrm{H}$ and ${ }^{13} \mathrm{C}\left\{{ }^{1} \mathrm{H}\right\}$ nuclear magnetic resonance (NMR) spectroscopy, and high-resolution matrix-assisted laser desorption/ionization time-of-flight mass spectrometry (HR-MALDI-ToF-MS). The later was instrumental to assign the dimensions of the macrocycles, which was further supported by their hydrodynamic radii deduced by the retention times in the GPC chromatogram (see Supporting Information, Figure S 31). The high symmetry of all obtained macrocycles is reflected in the respective ${ }^{1} \mathrm{H}$ - and ${ }^{13} \mathrm{C}\left\{{ }^{1} \mathrm{H}\right\}$-NMR spectra, which show remarkable differences in chemical shifts compared to starting material $\left(R_{\mathrm{p}}\right)$-S1 (see Figure $2 \mathrm{~b}$ ). 
a)
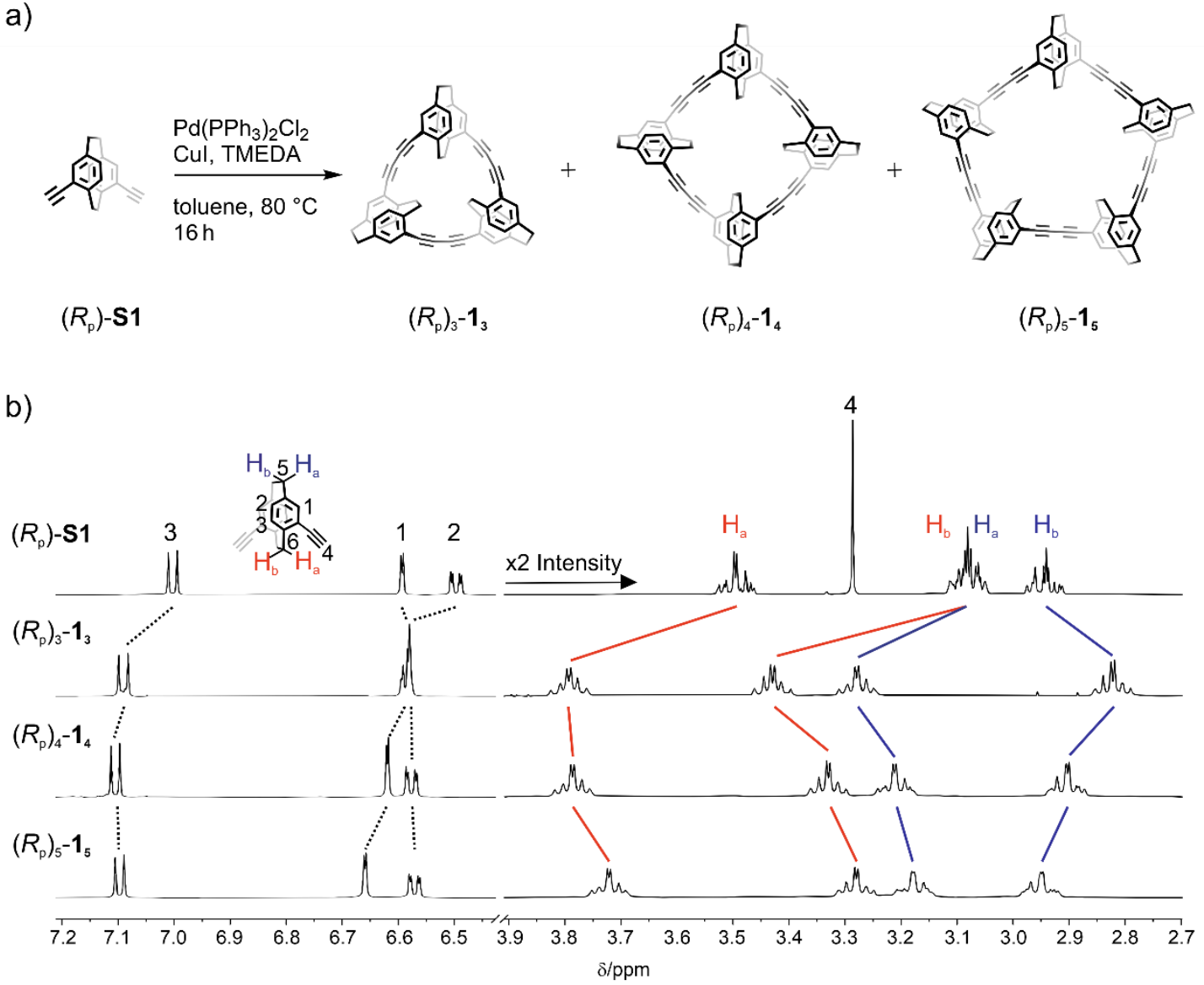

Figure 2. a) Synthetic scheme towards $\left(R_{\mathrm{p}}\right)_{3}-\mathbf{1}_{3},\left(R_{\mathrm{p}}\right)_{4}-\mathbf{1}_{4}$, and $\left(R_{\mathrm{p}}\right)_{5}-\mathbf{1}_{5}$. Synthesis of the $\left(S_{\mathrm{p}}\right)$ enantiomers was performed analogously. b) Comparison of the ${ }^{1} \mathrm{H}$ NMR spectra $\left(500 \mathrm{MHz}, \mathrm{CDCl}_{3}, 298 \mathrm{~K}\right)$ of $\left(R_{\mathrm{p}}\right)_{3}-\mathbf{1}_{\mathbf{3}},\left(R_{\mathrm{p}}\right)_{4}-\mathbf{1}_{4}$, and $\left(R_{\mathrm{p}}\right)_{5}-\mathrm{1}_{\mathrm{s}}$. For a better visibility, the intensity was doubled for the high field proton resonances. The NMR spectra of the $\left(S_{\mathrm{p}}\right)$-enantiomers are identical to the $\left(R_{\mathrm{p}}\right)$-enantiomers.

Comparing the ${ }^{1} \mathrm{H}$ NMR spectra of the starting material $\left(R_{\mathrm{p}}\right)-\mathrm{S} 1$ to the obtained macrocycles $\left(R_{\mathrm{p}}\right)_{3} \mathbf{1}_{3},\left(R_{\mathrm{p}}\right)_{4}-\mathbf{1}_{\mathbf{4}}$, and $\left(R_{\mathrm{p}}\right)_{5} \mathbf{1}_{5}$ in more detail (Figure $2 \mathrm{~b}$ ), the large difference in chemical shift of the ethane bridges $\left(\mathrm{H}_{5 / \mathrm{a}}\right.$ and $\left.\mathrm{H}_{6 a / b}\right)$ becomes apparent. The signal of proton $\mathrm{H}_{6 \mathrm{a}}$, which belongs to the inner ethane bridge of the PCP subunit in the macrocycles, is located at $3.49 \mathrm{ppm}$ for $\left(R_{\mathrm{p}}\right)$-S1. The signal shifts downfield by $0.3 \mathrm{ppm}$ to $3.79 \mathrm{ppm}$ and by 0.29 to $3.78 \mathrm{ppm}$ for $\left(R_{\mathrm{p}}\right)_{3}-\mathbf{1}_{3}$ and $\left(R_{\mathrm{p}}\right)_{4}-\mathbf{1}_{\mathbf{4}}$, respectively. The same proton for macrocycle $\left(R_{\mathrm{p}}\right)_{5}-\mathbf{1}_{5}$ is with $0.23 \mathrm{ppm}$ shifted less pronounced. Proton $\mathrm{H}_{6 \mathrm{~b}}$, which is connected to the same carbon atom as $\mathrm{H}_{6 \mathrm{a}}$ and thus also part of the inner ethane bridge of the PCP subunit in the macrocycles, is part of the same multiplet as the outer ethane proton $\mathrm{H}_{5 a}$ of $\left(R_{\mathrm{p}}\right)-\mathrm{S} \mathbf{1}$, residing at $3.08 \mathrm{ppm}$. For the macrocycles, however, the signals shifts downfield for $\left(R_{\mathrm{p}}\right)_{3}-\mathbf{1}_{\mathbf{3}},\left(R_{\mathrm{p}}\right)_{4}-\mathbf{1}_{\mathbf{4}}$, and $\left(R_{\mathrm{p}}\right)_{5}-\mathbf{1}_{5}$, by $0.34,0.25$, and $0.19 \mathrm{ppm}$, respectively. A very similar trend is observed for outer ethane bridge proton $\mathrm{H}_{5 \mathrm{a}}$, which is now clearly separated from $\mathrm{H}_{6 b}$. Its signal shifted from $3.08 \mathrm{ppm}$ to $3.28,3.21$, and $3.17 \mathrm{ppm}$ for $\left(R_{\mathrm{p}}\right)_{3}-\mathbf{1}_{3},\left(R_{\mathrm{p}}\right)_{4}-\mathbf{1}_{4}$, and $\left(R_{\mathrm{p}}\right)_{5}-\mathbf{1}_{5}$, respectively. The second proton of the outer ethane bridge, $\mathrm{H}_{5 b}$, is behaving rather 
differently, as it is upfield shifted by 0.12 and 0.04 ppm for $\left(R_{\mathrm{p}}\right)_{3}-\mathbf{1}_{3}$ and $\left(R_{\mathrm{p}}\right)_{4-14}$, respectively, but displays hardly any shift for pentameric macrocycle $\left(R_{\mathrm{p}}\right)_{5-15}$.

Concerning the aromatic protons, a very similar trend is observed, although the shifts tend to be less pronounced than for the ethane bridge protons. The doublet of proton $\mathrm{H}_{3}$, which is at $7.00 \mathrm{ppm}$ for $\left(R_{\mathrm{p}}\right)$-S1, shifts downfield to 7.09, 7.10, and 7.09 ppm for $\left(R_{\mathrm{p}}\right)_{3}-\mathbf{1}_{3},\left(R_{\mathrm{p}}\right)_{4}-\mathbf{1}_{4}$, and $\left(R_{\mathrm{p}}\right)_{5}-\mathbf{1}_{5}$, respectively. Doublet of doublets of $\mathrm{H}_{2}$ shifts from 6.49 ppm to 6.58 ppm for $\left(R_{\mathrm{p}}\right)_{3} \mathbf{1}_{\mathbf{3}}$, but then stays with 6.57 and $6.56 \mathrm{ppm}$ for $\left(R_{\mathrm{p}}\right)_{4} \mathbf{- 1 4}$ and $\left(R_{\mathrm{p}}\right)_{5}-\mathbf{1 5}_{5}$, respectively, fairly comparable. Proton $\mathrm{H}_{1}$ receives a small upfield shift of 0.01 ppm for trimer $\left(R_{\mathrm{p}}\right)_{3} \mathbf{1}_{3}$, followed by a downfield shift to 6.61 and $6.65 \mathrm{ppm}$ for $\left(R_{\mathrm{p}}\right)_{4-\mathbf{1}_{4}}$ and $\left(R_{\mathrm{p}}\right)_{5}-\mathbf{1}_{5}$, respectively. Generally, no structure related apparent rationale can be concluded from the chemical shifts of the individual protons. However, the largest differences in chemical shifts were observed for trimeric macrocycle $\left(R_{p}\right)_{3}-\mathbf{1}_{3}$, attributed to the higher strain, leading to a more pronounced geometric disorder as compared to the other macrocycles. The ${ }^{13} \mathrm{C}\left\{{ }^{1} \mathrm{H}\right\}$ NMR spectra show 10 signals for each of the macrocycles and the starting material, being consistent with the expected high symmetry of the obtained structures (see Supporting Information, Figures S 10, S 17 and S 24).

\section{Optical Properties}

The absorption and emission spectra of the dialkyne $\left(R_{\mathrm{p}}\right)-\mathbf{S} 1$ are compared to the obtained macrocycles in Figure 3. The highest wavelength transition $\left(\lambda_{\max }\right)$ of $\left(R_{\mathrm{p}}\right)$-S1 lies at $285 \mathrm{~nm}$ with an extinction coefficient $(\varepsilon)$ of $9308 \mathrm{~L} \mathrm{M}^{-1} \mathrm{~cm}^{-1}$. The measured emission peak has its maxima at $382 \mathrm{~nm}$, resulting in a large Stokes shift of $97 \mathrm{~nm}$. On the other hand, trimeric macrocycle $\left(R_{\mathrm{p}}\right)_{3} \mathbf{1}_{3}$ displays two main absorption bands at 331 and $369 \mathrm{~nm}\left(\lambda_{\max }\right)$ with $\varepsilon=68206$ and $46182 \mathrm{~L} \mathrm{M}^{-1} \mathrm{~cm}^{-1}$, respectively. Likewise, the normalized emission spectrum features two main bands at $385 \mathrm{~nm}$ and $418 \mathrm{~nm}$, resulting in quite a small Stokes shift of $16 \mathrm{~nm}$. The much smaller Stokes shift is unsurprising, given the expected increased rigidity of the macrocycle as compared to the dialkyne $\left(R_{\mathrm{p}}\right)$-S1. The two main absorption bands of $\left(R_{\mathrm{p}}\right)_{4}-\mathbf{1}_{4}$ lie at $339(\varepsilon=89567$ $\left.\mathrm{L} \mathrm{M}^{-1} \mathrm{~cm}^{-1}\right)$ and $370 \mathrm{~nm}\left(\lambda_{\max }, \varepsilon=80525 \mathrm{~L} \mathrm{M}^{-1} \mathrm{~cm}^{-1}\right)$, and for $\left(R_{\mathrm{p}}\right)_{5-1}{ }_{5}$ at $341(\varepsilon=147$ $\left.355 \mathrm{~L} \mathrm{M}^{-1} \mathrm{~cm}^{-1}\right)$ and $370 \mathrm{~nm}\left(\lambda_{\max }, \varepsilon=149778 \mathrm{~L} \mathrm{M}^{-1} \mathrm{~cm}^{-1}\right)$. Aside from the increasing extinction coefficient, the absorption spectra change insignificantly with increasing ring 
size and likewise the normalized emission spectra are almost identical for all three macrocycles.
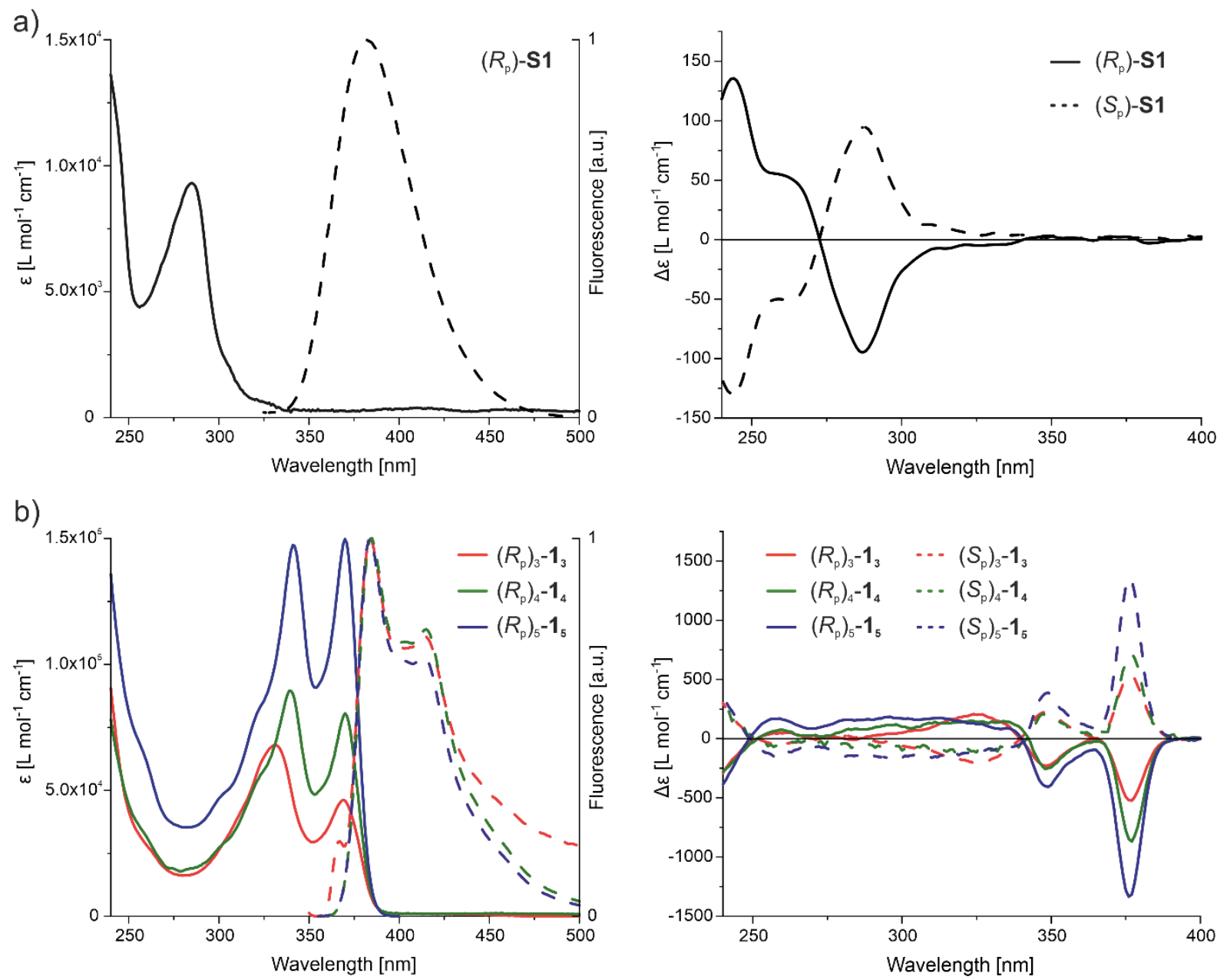

Figure 3. a) Left: Absorption (solid line) and emission (dashed line, excitation at $285 \mathrm{~nm}$ ) spectra of $\left(R_{\mathrm{p}}\right)$-S1 in $\mathrm{CH}_{2} \mathrm{Cl}_{2}\left(c \sim 10^{-6} \mathrm{M}\right)$. Right: Circular dichroism spectra of $\left(R_{\mathrm{p}}\right)$-S1 (solid line) and $\left(S_{\mathrm{p}}\right)$-S1 (dashed line) in $\mathrm{CH}_{2} \mathrm{Cl}_{2}(c$ $\left.\sim 10^{-6} \mathrm{M}\right)$. b) Left: Absorption (solid line) and emission (dashed line) spectra of $\left(R_{\mathrm{p}}\right)_{3} \mathbf{- 1}_{\mathbf{3}}(\mathrm{red}),\left(R_{\mathrm{p}}\right)_{4}-\mathbf{1}_{\mathbf{4}}(\mathrm{green})$, and $\left(R_{\mathrm{p}}\right)_{5-15}$ (blue) in $\mathrm{CH}_{2} \mathrm{Cl}_{2}\left(c \sim 10^{-6} \mathrm{M}\right)$. Compounds $\left(R_{\mathrm{p}}\right)_{3}-\mathbf{1}_{3},\left(R_{\mathrm{p}}\right)_{4}-\mathbf{1}_{4}$, and $\left(R_{\mathrm{p}}\right)_{5}-\mathbf{1}_{5}$ were excited at 330, 340, and 340 $\mathrm{nm}$, respectively. Absorption and emission spectra were comparable for the $\left(S_{\mathrm{p}}\right)$-enantiomers. Right: Circular dichroism spectra of the $\left(R_{\mathrm{p}}\right)$-enantiomers (solid line) and $\left(S_{\mathrm{p}}\right)$-enantiomers (dashed line) of $\mathbf{1}_{\mathbf{3}}$ (red), $\mathbf{1}_{\mathbf{4}}$ (green) and 15 (blue) in $\mathrm{CH}_{2} \mathrm{Cl}_{2}\left(c \sim 10^{-6} \mathrm{M}\right)$.

In the circular dichroism (CD) spectra, dialkyne $\left(R_{\mathrm{p}}\right)$-S1 shows three main cotton bands at 287, 262 and $244 \mathrm{~nm}$ with moderate molar circular dichroism values $(\Delta \varepsilon)$ of $-94,52$ and $135 \mathrm{~L} \mathrm{~mol}^{-1} \mathrm{~cm}^{-1}$, respectively. Compared to that, trimeric macrocycle $\left(R_{\mathrm{p}}\right)_{3}-\mathbf{1}_{3}$ shows two main cotton bands at 349 and $377 \mathrm{~nm}$ with strong molar circular dichroism values of -256 and $-523 \mathrm{~L} \mathrm{~mol}^{-1} \mathrm{~cm}^{-1}$. Just as in the absorption spectra, the main peaks in the CD spectra do not shift in energy when increasing the ring size, but the molar circular dichroism value increase drastically. The cotton bands of $\left(R_{\mathrm{p}}\right)_{4-\mathbf{1}_{4}}$ show 
particularly strong molar circular dichroism values of -847 for the transition at $377 \mathrm{~nm}$ and $\left(R_{\mathrm{p}}\right)_{5}-15$ shows extraordinarily intense values of $-1335 \mathrm{~L} \mathrm{~mol}^{-1} \mathrm{~cm}^{-1}$. To the best of our knowledge, this is the most intense molar circular dichroism value for macrocyclic all-carbon molecules reported to date, surpassing those of alleno-acetylenic macrocycles ${ }^{33}$ and also of helicene oligomers. ${ }^{34}$ Interestingly, the molar circular dichroism values increase non-linearly with the number of subunits present in the macrocycles, which has been previously also reported for other types of molecules. ${ }^{33,35}$ Specifically, the intensity of the cotton effects increases 1.7 times for $\left(R_{\mathrm{p}}\right)_{4}-\mathbf{1}_{4}$ compared to $\left(R_{\mathrm{p}}\right)_{3}-\mathbf{1 3}$, and 1.6 times for $\left(R_{\mathrm{p}}\right)_{5-15}$ compared to $\left(R_{\mathrm{p}}\right)_{4-14}$, although the number of subunits increases just by 1.33 and 1.25 , respectively.

Table 1. Comparison of the main absorption, emission and circular dichroism values of $\left(R_{\mathrm{p}}\right)-\mathrm{S} \mathbf{1}_{1},\left(R_{\mathrm{p}}\right)_{3}-\mathbf{1}_{3},\left(R_{\mathrm{p}}\right)_{4}-\mathbf{1}_{4}$ and $\left(R_{\mathrm{p}}\right)_{5}-\mathbf{1}_{5}$.

\begin{tabular}{|c|c|c|c|c|}
\hline Comp. & $\lambda_{\max }[\mathrm{nm}]$ & $\varepsilon_{\lambda \max }\left[\mathrm{L} \mathrm{mol}^{-1} \mathrm{~cm}^{-1}\right]$ & $\lambda_{\mathrm{em}}($ excitation) $[\mathrm{nm}]$ & $\Delta \varepsilon_{\max }\left[\mathrm{L} \mathrm{mol}^{-1} \mathrm{~cm}^{-1}\right]$ \\
\hline$\left(R_{\mathrm{p}}\right)-\mathrm{S} 1$ & 285 & 9308 & $382(285)$ & 135 \\
\hline$\left(R_{\mathrm{p}}\right)_{3}-\mathbf{1}_{3}$ & 369 & 46182 & $385,418(330)$ & -523 \\
\hline$\left(R_{\mathrm{p}}\right)_{4}-\mathbf{1}_{4}$ & 370 & 80525 & $385,418(340)$ & -847 \\
\hline$\left(R_{\mathrm{p}}\right)_{5}-\mathbf{1}_{5}$ & 370 & 149778 & $385,418(340)$ & -1335 \\
\hline
\end{tabular}

The g-factor plot was analyzed in order to get an understanding of the origin of the intense chiroptical response that the macrocycles display. The g-factor, which is also known as the anisotropy or dissymmetry factor, is defined as the ratio of molar circular dichroism and molar extinction $(\Delta \varepsilon / \varepsilon)$ and provides information about the magnetic contribution to a given cotton effect. ${ }^{36}$ The plot shows similar contributions for all three macrocycles $\left(R_{\mathrm{p}}\right)_{3} \mathbf{1}_{\mathbf{3}},\left(R_{\mathrm{p}}\right)_{4}-\mathbf{1}_{4}$, and $\left(R_{\mathrm{p}}\right)_{5}-\mathbf{1}_{5}$, with $\mathrm{g}$-factor values reaching moderate values of up to 0.019 (see Supporting Information, Figure $S$ 35). The non-linear increase of the chiroptical response can hence not be explained by an additive magnetic contribution to the transition but is rather originating from a non-linear increase in contribution of the electronic transition dipole moment, which is consistent with the strong increase in molar extinction values. Since there is only a small flattening of the non-linear increase observed, a potential hexameric macrocycle would result in an even larger cotton effect. However, such a macrocycle was not observed in the obtained crude mixture and is thus deemed a geometrically unfavoured structure. 


\section{Conjugated System}

When comparing conjugated systems with similar substituents, a redshift in the absorption spectra is associated with an increase of the conjugation length. Given the observation that the highest wavelength transition $\lambda_{\max }$ in the absorption spectrum converges to $370 \mathrm{~nm}$ upon enlarging the ring size, the question arises whether the conjugation pathways are interrupted or whether the system is conjugated effectively. To investigate on this matter, commercially available compound $\mathbf{2}$ and literature known molecule $3^{37}$ were identified as relevant reference compounds. Namely, 1,4diphenylbutadiyne (2) would make up the simplest conjugated subsystem of the macrocycles if no coupling through the PCP core existed. On the other hand, compound $\mathbf{3}$ would manifest the smallest subsystem if conjugation is interrupted beyond one PCP core (Figure 4a).

a)

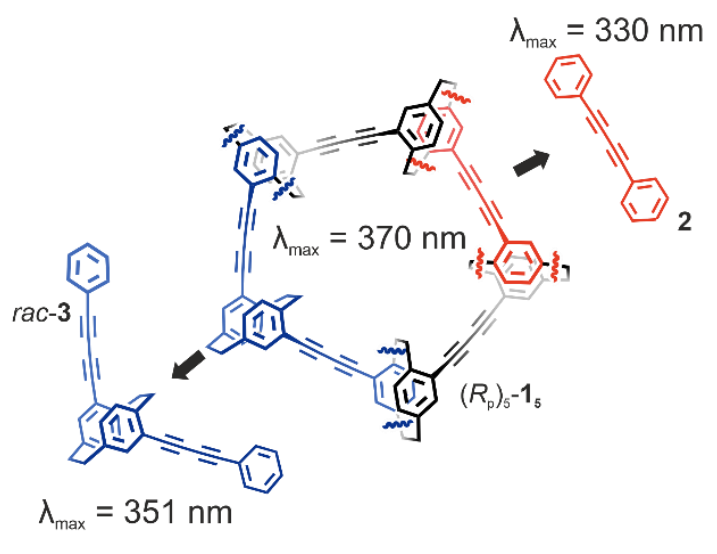

b)

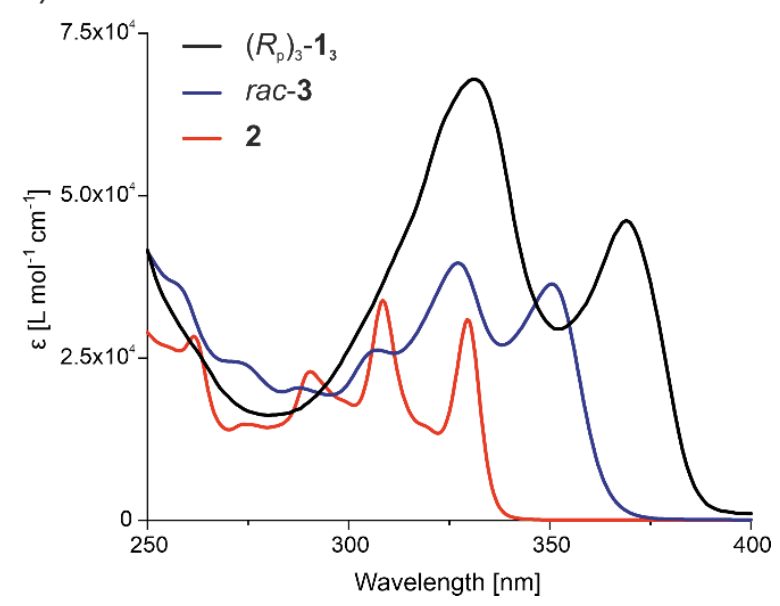

Figure 4. a) Reference compounds 2 and 3 which manifest small sub-segments of the macrocycles are displayed together with their highest wavelength transition $\lambda_{\max }$. b) Absorption spectra of 2 (red), rac-3 (blue) and $\left(R_{p}\right)_{3}-\mathbf{1}_{3}$ (black) in $\mathrm{CH}_{2} \mathrm{Cl}_{2}\left(c \sim 10^{-6} \mathrm{M}\right)$.

The absorption spectra of the reference compounds are compared to the trimeric $\left(R_{\mathrm{p}}\right)_{3}-\mathbf{1}_{3}$ in Figure $4 \mathrm{~b}$. The highest wavelength transition $\lambda_{\max }$ for 2 lies at $330 \mathrm{~nm}$, which is redshifted by $21 \mathrm{~nm}$ to $351 \mathrm{~nm}$ for reference compound 3 . This observation suggests efficient conjugation through the pseudo-meta PCP moiety. Taking into account that $\lambda_{\max }$ for $\left(R_{\mathrm{p}}\right)_{3}-\mathbf{1}_{3}$ is further redshifted by $18 \mathrm{~nm}$ to $369 \mathrm{~nm}$ as compared to 3 and that $\lambda_{\max }$ converges to $370 \mathrm{~nm}$ when increasing the ring size, we concluded that the conjugated system is extended beyond one PCP core and that it is efficiently 
conjugated throughout the whole macrocyclic backbone. This conclusion is further supported by the absorption spectra of fast eluting bands in the GPC chromatogram (see Supporting Information, Figures S 31 - S 34). The absorption spectra of these fast eluting compounds (presumably non-cyclized polymers) display a nearly identical shape as the macrocycles $\left(R_{\mathrm{p}}\right)_{3}-\mathbf{1}_{3},\left(R_{\mathrm{p}}\right)_{4}-\mathbf{1}_{\mathbf{4}}$, and $\left(R_{\mathrm{p}}\right)_{5}-\mathbf{1}_{5}$, and their $\lambda_{\max }$ is converging from $368 \mathrm{~nm}$ toward $370 \mathrm{~nm}$. This finding suggests that these macrocycles are so efficiently conjugated that they obtain an astonishing polymer-like conjugation length despite their rather small size.

\section{Conclusion}

We could show that the angle offered by pseudo-meta substituted PCPs allows to construct trimeric-, tetrameric- and pentameric 1,3-butadiyne linked macrocycles $\left(R_{\mathrm{p}}\right)_{3} \mathbf{1}_{3}, \quad\left(R_{\mathrm{p}}\right)_{4}-\mathbf{1 4}_{4}$, and $\left(R_{\mathrm{p}}\right)_{5}-\mathbf{1}_{5}$, respectively. The electronic through space communication of the pseudo-meta PCPs evidently leads to a thoroughly conjugated system, yielding polymer-like states already for the smallest of the macrocycles in the studied series. The inherent chirality of the pseudo-meta PCPs leads to a strong chiroptic response manifested in the non-linearly increasing CD signals from $\mathbf{1} \mathbf{3}$ to $\mathbf{1 5}$ with unrivalled molar circular dichroism values for all-carbon systems of up to $-1335 \mathrm{~L}$ $\mathrm{mol}^{-1} \mathrm{~cm}^{-1}$ for $\left(R_{\mathrm{p}}\right)_{5-1}$. These findings prove pseudo-meta PCP to be viable corner unit for the construction of various 3D functional materials, and suggest efficient incorporation into $\pi$-conjugated material that would otherwise suffer from unfavourable strain energies. We are currently looking into DFT calculations to get a deeper understanding of the origin of the intense chiroptic response and plan to investigate the CPL properties of the obtained macrocycles.

\section{Acknowledgement}

The authors acknowledge generous financial support by the Swiss National Science Foundation (SNF grant number 200020-178808) and by the 111 project (9000218011002). The study was further partially funded by the FET open project QuIET (no. 767187). 


\section{Conflict of Interest}

The authors declare no conflict of interest.

\section{References}

[1] Jasti, R.; Bhattacharjee, J.; Neaton, J. B.; Bertozzi, C. R. Synthesis, Characterization, and Theory of [9]-, [12]-, and [18]Cycloparaphenylene: Carbon Nanohoop Structures. J. Am. Chem. Soc. 2008, 130 (52), 1764617647.

[2] Yamago, S.; Watanabe, Y.; Iwamoto, T. Synthesis of [8]Cycloparaphenylene from a Square-Shaped Tetranuclear Platinum Complex. Angew. Chem. Int. Ed. 2010, 49 (4), 757-759.

[3] Takaba, H.; Omachi, H.; Yamamoto, Y.; Bouffard, J.; Itami, K. Selective Synthesis of [12]Cycloparaphenylene. Angewandte Chemie International Edition 2009, 48 (33), 6112-6116.

[4] Omachi, H.; Matsuura, S.; Segawa, Y.; Itami, K. A Modular and Size-Selective Synthesis of [n]Cycloparaphenylenes: A Step toward the Selective Synthesis of [n,n] Single-Walled Carbon Nanotubes. Angew. Chem. Int. Ed. 2010, 49 (52), 10202-10205.

[5] Cheung, K. Y.; Watanabe, K.; Segawa, Y.; Itami, K. Synthesis of a Zigzag Carbon Nanobelt. Nat. Chem. 2021, 13 (3), 255-259.

[6] Kawase, T.; Darabi, H. R.; Oda, M. Cyclic [6]- and [8]Paraphenylacetylenes. Angew. Chem. Int. Ed. 1996, 35 (22), 2664-2666.

[7] Povie, G.; Segawa, Y.; Nishihara, T.; Miyauchi, Y.; Itami, K. Synthesis of a Carbon Nanobelt. Science 2017.

(8) Shortreed, M. R.; Swallen, S. F.; Shi, Z.-Y.; Tan, W.; Xu, Z.; Devadoss, C.; Moore, J. S.; Kopelman, R. Directed Energy Transfer Funnels in Dendrimeric Antenna Supermolecules. J. Phys. Chem. B 1997, 101 (33), 6318-6322.

(9) Xu, Z.; Moore, J. S. Rapid Construction of Large-Size Phenylacetylene Dendrimers up to 12.5 Nanometers in Molecular Diameter. Angew. Chem. Int. Ed. 1993, 32 (9), 1354-1357.

[10] Shetty, A. S.; Zhang, J.; Moore, J. S. Aromatic m-Stacking in Solution as Revealed through the Aggregation of Phenylacetylene Macrocycles. J. Am. Chem. Soc. 1996, 118 (5), 1019-1027.

[11] Höger, S.; Rosselli, S.; Ramminger, A.-D.; Enkelmann, V. A Facile Synthesis of Large Extraannular-Functionalized Phenyl-Ethynyl Macrocycles Containing mTerphenyl Units. Org. Lett. 2002, 4 (24), 4269-4272.

[12] Shu, L.; Müri, M.; Krupke, R.; Mayor, M. Shape-Persistent Macrocycles Comprising Perfluorinated Benzene Subunits: Synthesis, Aggregation 
Behaviour and Unexpected $\mu$-Rod Formation. Org. Biomol. Chem. 2009, 7 (6), 1081-1092.

[13] Tobe, Y.; Utsumi, N.; Nagano, A.; Naemura, K. Synthese und Assoziationsverhalten von [4.4.4.4.4.4]Metacyclophandodecain-Derivaten mit Bindungsstellen innerhalb des Makrocyclus. Angew. Chem. 1998, 110 (9), 1347-1349.

[14] Mayor, M.; Lehn, J.-M. Reducible Nanosize Macrocycles. J. Am. Chem. Soc. 1999, 121 (48), 11231-11232.

[15] Shu, L.; Mayor, M. Shape-Persistent Macrocycle with a Self-Complementary Recognition Pattern Based on Diacetylene-Linked Alternating Hexylbenzene and Perfluorobenzene Rings. Chem. Commun. 2006, No. 39, 4134-4136.

[16] Kandre, R.; Schlüter, A. D. Polyarylene Synthesis by Suzuki Polycondensation of Aryl Dichlorides and an Aryl Diboronic Acid Ester. Macromol. Rapid Commun. 2008, 29 (20), 1661-1665.

[17] Kandre, R. M.; Kutzner, F.; Schlaad, H.; Schlüter, A. D. Synthesis of High Molecular Weight Amphiphilic Polyphenylenes by Suzuki Polycondensation. Macromol. Chem. Phys. 2005, 206 (16), 1610-1618.

[18] Lovell, T. C.; Colwell, C. E.; Zakharov, L. N.; Jasti, R. Symmetry Breaking and the Turn-on Fluorescence of Small, Highly Strained Carbon Nanohoops. Chem. Sci. 2019, 10 (13), 3786-3790.

[19] lyoda, M.; Yamakawa, J.; Rahman, M. J. Conjugated Macrocycles: Concepts and Applications. Angew. Chem. Int. Ed. 2011, 50 (45), 10522-10553.

[20] Gregorius, H.; Baumgarten, M.; Renter, R.; Müllen, K.; Tyutyulkov, N. MetaPhenylene Units as Conjugation Barriers in Phenylenevinylene Chains. Angew. Chem. Int. Ed. 1992, 31 (12), 1653-1655.

[21] Weiland, K. J.; Gallego, A.; Mayor, M. Beyond Simple Substitution Patterns Symmetrically Tetrasubstituted [2.2]Paracyclophanes as 3D Functional Materials: Beyond Simple Substitution Patterns - Symmetrically Tetrasubstituted [2.2]Paracyclophanes as 3D Functional Materials. Eur. J. Org. Chem. 2019, 2019 (20), 3073-3085.

[22] Gon, M.; Morisaki, Y.; Sawada, R.; Chujo, Y. Synthesis of Optically Active, XShaped, Conjugated Compounds and Dendrimers Based on Planar Chiral [2.2]Paracyclophane, Leading to Highly Emissive Circularly Polarized Luminescence. Chem. Eur. J. 2016, 22 (7), 2291-2298.

[23] Gon, M.; Morisaki, Y.; Chujo, Y. A Silver( I )-Induced Higher-Ordered Structure Based on Planar Chiral Tetrasubstituted [2.2]Paracyclophane. Chem. Commun. 2017, 53 (59), 8304-8307.

[24] Morisaki, Y.; Sawada, R.; Gon, M.; Chujo, Y. New Types of Planar Chiral [2.2]Paracyclophanes and Construction of One-Handed Double Helices. Chem. Asian J. 2016, 4.

[25] Wu, Y.; Zhuang, G.; Cui, S.; Zhou, Y.; Wang, J.; Huang, Q.; Du, P. ThroughSpace $\pi$-Delocalization in a Conjugated Macrocycle Consisting of [2.2]Paracyclophane. Chem. Commun. 2019, 55 (97), 14617-14620. 
[26] Weiland, K. J.; Brandl, T.; Atz, K.; Prescimone, A.; Häussinger, D.; Šolomek, T.; Mayor, M. Mechanical Stabilization of Helical Chirality in a Macrocyclic Oligothiophene. J. Am. Chem. Soc. 2019, 141 (5), 2104-2110.

[27] Hasegawa, M.; Ishida, Y.; Sasaki, H.; Ishioka, S.; Usui, K.; Hara, N.; Kitahara, M.; Imai, Y.; Mazaki, Y. Helical Oligophenylene Linked with

[2.2]Paracyclophane: Stereogenic $\pi$-Conjugated Dye for Highly Emissive Chiroptical Properties. Chem. Eur. J. 2021, 27, 16225-16231.

[28] Morisaki, Y.; Inoshita, K.; Chujo, Y. Planar-Chiral Through-Space Conjugated Oligomers: Synthesis and Characterization of Chiroptical Properties. Chem. Eur. J. 2014, 20 (27), 8386-8390.

[29] Morisaki, Y.; Gon, M.; Sasamori, T.; Tokitoh, N.; Chujo, Y. Planar Chiral Tetrasubstituted [2.2]Paracyclophane: Optical Resolution and Functionalization. J. Am. Chem. Soc. 2014, 136 (9), 3350-3353.

[30] Li, X.; Staykov, A.; Yoshizawa, K. Orbital Views on Electron-Transport Properties of Cyclophanes: Insight into Intermolecular Transport. BCSJ 2012, 85 (2), 181-188.

[31] Reznikova, K.; Hsu, C.; Schosser, W. M.; Gallego, A.; Beltako, K.; Pauly, F.; van der Zant, H. S. J.; Mayor, M. Substitution Pattern Controlled Quantum Interference in [2.2]Paracyclophane-Based Single-Molecule Junctions. J. Am. Chem. Soc. 2021, 143 (34), 13944-13951.

[32] Meyer-Eppler, G.; Sure, R.; Schneider, A.; Schnakenburg, G.; Grimme, S.; Lützen, A. Synthesis, Chiral Resolution, and Absolute Configuration of Dissymmetric 4,15-Difunctionalized [2.2]Paracyclophanes. J. Org. Chem. 2014, 79 (14), 6679-6687.

[33] Alonso-Gómez, J. L.; Rivera-Fuentes, P.; Harada, N.; Berova, N.; Diederich, F. An Enantiomerically Pure Alleno-Acetylenic Macrocycle: Synthesis and Rationalization of Its Outstanding Chiroptical Response. Angew. Chem. Int. Ed. 2009, 48 (30), 5545-5548.

[34] Schaack, C.; Sidler, E.; Trapp, N.; Diederich, F. Helical Threads: Enantiomerically Pure Carbo[6]Helicene Oligomers. Chem. Eur. J. 2017, 23 (57), 14153-14157. https://doi.org/10.1002/chem.201703024.

[35] Roose, J.; Achermann, S.; Dumele, O.; Diederich, F. Electronically Connected [n] Helicenes: Synthesis and Chiroptical Properties of Enantiomerically Pure (E)-1,2-Di([6]Helicen-2-YI)Ethenes. Eur. J. Org. Chem. 2013, 2013 (16), 32233231.

[36] Snatzke, G. Circulardichroismus und absolute Konformation: Anwendung der qualitativen MO-Theorie auf die chiroptischen Phänomene. Angew. Chem. 1979, 91 (5), 380-393.

[37] Hopf, H.; Dix, I. Ethynyl[2.2]Paracyclophanes as Building Blocks for Extended T-Systems. Synlett 2006, 2006 (09), 1416-1418. 